\title{
Early interactions of Flavobacterium psychrophilum with macrophages of rainbow trout Oncorhynchus mykiss
}

\author{
Amin Nematollahi*, Frank Pasmans, Freddy Haesebrouck, Annemie Decostere \\ Laboratory of Veterinary Bacteriology and Mycology, Department of Pathology, Bacteriology and Avian Diseases, \\ Faculty of Veterinary Medicine, Ghent University, Salisburylaan 133, 9820 Merelbeke, Belgium
}

\begin{abstract}
The early interactions of a low and a highly virulent Flavobacterium psychrophilum strain with head kidney and spleen macrophages of rainbow trout Oncorhynchus mykiss were characterized. The highly virulent strain was killed 5.8 to 11 times less frequently than the low virulent strain. The head kidney macrophages showed a microbicidal activity approximately twice as high as that of the spleen macrophages. A 2- to 3-fold higher production of reactive oxygen species (ROS) was induced by the highly virulent strain than by the low virulent one. The head kidney macrophages produced approximately twice as much ROS as the spleen macrophages. The low virulent strain was killed approximately 10 times more frequently by $\mathrm{H}_{2} \mathrm{O}_{2}$ than was the highly virulent strain. In spleen macrophages, the highly virulent strain caused twice as much cytotoxic effects compared to the low virulent strain. In conclusion, virulence in F. psychrophilum appears to be correlated with higher $O$. mykiss macrophage cytotoxicity and resistance to ROS and, therefore, with enhanced resistance to bacterial killing. Moreover, due to lower ROS production, spleen macrophages have a lower antimicrobial action against F. psychrophilum, compared to head kidney macrophages and, thus, might form a 'safe site' in which bacteria can reside.
\end{abstract}

KEY WORDS: Rainbow trout $\cdot$ Flavobacterium psychrophilum $\cdot$ Macrophage $\cdot$ Cytotoxic $\cdot$ Reactive oxygen species

Resale or republication not permitted without written consent of the publisher

\section{INTRODUCTION}

Flavobacterium psychrophilum is a Gram-negative filamentous chromogenic rod shaped bacterium (Bernardet et al. 1996) which was formerly called Cytophaga psychrophila or Flexibacter psychrophilus (Borg 1960, Holt et al. 1993). This bacterium is the causal agent of bacterial cold water disease (BCWD), where the primary target group for the disease is adult salmonids, and rainbow trout fry syndrome (RTFS), a disease characterized by high mortality (up to $70 \%$ ) of rainbow trout Oncorhynchus mykiss fry and fingerlings (Bruno 1992, Austin \& Austin 1999, Nematollahi et al. 2003). F. psychrophilum was initially isolated from the kidney and external lesions of diseased juvenile coho salmon Oncorhynchus kisutch in the USA (Borg 1960), and the pathology of the disease caused by this organism had been described earlier by Davis (1946) in rainbow trout.

In spite of the importance of Flavobacterium psychrophilum as a fish pathogen and the increasing significance of the disease, the data relating to its pathogenesis are still scarce. Several studies imply that macrophages play a major role in the pathogenesis of F. psychrophilum infections in rainbow trout. The presence of phagosomes and residual bodies within spleen phagocytes of naturally infected fry suggests extensive lysosomal activity (Rangdale et al. 1999). Lammens et al. (2000) proved that F. psychrophilum and their metabolites were able to induce the production of reactive oxygen species (ROS) in head kidney phagocytes. This group also demonstrated that spleen phagocytic cells of experimentally infected fry contained an increasing number of viable $F$. psychro- 
philum bacteria, but only on the highly virulent strain and in the course of time (Decostere et al. 2001). Based on these data, one might speculate that F. psychrophilum virulence is associated with interactions with the host macrophages. The present study aims at deciphering in greater depth the association between bacterial virulence and early interactions of F. psychrophilum with rainbow trout macrophages.

\section{MATERIALS AND METHODS}

Fish. Thirty rainbow trout Oncorhynchus mykiss weighing between 500 and $800 \mathrm{~g}$ were obtained from a commercial fish farm (Dilbeek, Belgium), where Flavobacterium psychrophilum infections had never before been diagnosed. The fish were kept in a flowthrough system (2000 l tank) containing aerated well water $\left(12\right.$ to $\left.14^{\circ} \mathrm{C}\right)$ for $3 \mathrm{wk}$ prior to experimentation (pH 7.6; total hardness 100 ppm; $\mathrm{NH}_{3}<0.01 \mathrm{ppm} ; \mathrm{NO}_{2}$ $<0.01 \mathrm{ppm}$; dissolved oxygen $9 \mathrm{ppm}$ ). The fish were fed daily with a commercial diet (Trouvit Perle Response 2000, Trouw). All fish were evaluated clinically before inclusion in the experiments as described below. Samples were taken from the skin, fins and gills for evaluation of external parasitic infestation. Wet mount preparations were then made and examined microscopically. The fish were clinically healthy and found to be free of external parasite infestations. The presence of $F$. psychrophilum was assessed by streaking swabs from the skin and gills onto Shieh agar (Shieh 1980). Plates were incubated at $17^{\circ} \mathrm{C}$ for $5 \mathrm{~d}$. F. psychrophilum was not isolated from any of the collected samples.

Bacterial strains. Two Flavobacterium psychrophilum strains were used: Dubois and 99/10A. Strain Dubois was isolated from the spleen of a fish from an RTFS outbreak in Belgium, which resulted in $70 \%$ mortality. Strain 99/10A was recovered in Denmark from the internal organs of healthy rainbow trout (Madsen \& Dalsgaard 1998). In order to preserve virulent properties, both strains were stored virtually immediately following in vivo isolation in $-70^{\circ} \mathrm{C}$ in lyophilization medium (LYM) containing $6 \mathrm{~g}$ glucose (Merck), $20 \mathrm{ml}$ Brain Heart Infusion (BHI, Oxoid) and $60 \mathrm{ml}$ sterile horse serum (Gibco). After intraperitoneal inoculation, Strain Dubois proved to be highly virulent whereas Strain 99/10A was found to be of low virulence (Madsen \& Dalsgaard 1998, Decostere et al. 2001).

Stock suspensions of the 2 strains were stored at $-70^{\circ} \mathrm{C}$. After thawing, the bacteria were grown for $4 \mathrm{~d}$ in $4 \mathrm{ml}$ of Shieh broth at $17^{\circ} \mathrm{C}$. Subsequently, subcultures were incubated for $4 \mathrm{~d}$ at $17^{\circ} \mathrm{C}$. The cultured broth was centrifuged $\left(3000 \times g, 10 \mathrm{~min}, 17^{\circ} \mathrm{C}\right)$ and the resulting pellet and supernatant were separated. The pellet was re-suspended in Dulbecco's Modified Eagle Medium (DMEM, Gibco) without phenol red. The number of colony forming units (CFU) was determined by plating 10 -fold serial dilutions on Shieh agar plates, and the bacterial suspension was diluted with DMEM to the desired concentration.

Collection of macrophages from the head kidney and spleen of rainbow trout. Head kidney and spleen macrophages were collected according to the procedures of Lammens et al. (2000) with some modifications. Briefly, fish were humanely killed using an overdose of a solution of benzocaine (ethylaminobenzoate) in ethanol (w/v $0.1 \mathrm{~g} \mathrm{ml}^{-1}$ ). The spleen and head kidney were aseptically removed and pushed through a $150 \mu \mathrm{m}$ nylon mesh (Solana) in DMEM medium containing $5 \%$ foetal calf serum (FCS, Jitegro, aaDierea), $1 \%$ non-essential amino acids (Gibco), $1 \%$ glutamine (Gibco), $100 \mathrm{IU} \mathrm{ml}^{-1}$ penicillin (Gibco), $100 \mathrm{mg} \mathrm{ml}^{-1}$ streptomycin (Gibco), $100 \mathrm{mg} \mathrm{ml}^{-1}$ kanamycin sulphate (Gibco) and $10 \mathrm{IU} \mathrm{ml}^{-1}$ heparin (Leo Pharmaceutical Products). The cell suspension was layered on top of a discontinuous 34 to $51 \%$ Percoll gradient (Pharmacia Biotech). After centrifugation $\left(400 \times g, 25 \mathrm{~min}, 4^{\circ} \mathrm{C}\right)$, the band of cells at the 34 to $51 \%$ interface was collected and washed once with sterile Hanks' balanced salt solution (HBSS) without $\mathrm{Ca}$ and $\mathrm{Mg}$ (Gibco).

Subsequently, the cells were re-suspended in DMEM medium. The cell population purity was checked using Haemacolor ${ }^{\circledR}$ staining (Merck) and the $\alpha$-naphtyl butyrate esterase staining kit (Sigma Diagnostic). Esterase positive cells were classified as macrophages. The average percentage of esterase positive cells (macrophages) was more than $95 \%$ of the cells in suspension. The cells were counted using a Burker counting chamber, and their viability was determined by exclusion of trypan blue. Loss of cell membrane permeability in damaged cells results in uptake of trypan blue, whereas in viable cells the dye is excluded. Macrophage viability exceeded $98 \%$. The cell suspension was then adjusted to $10^{7}$ macrophages $\mathrm{ml}^{-1}$ and $100 \mu \mathrm{l}$ volumes were cultivated in 96 well plates. After $24 \mathrm{~h}$ incubation, the wells were gently washed 3 times with HBSS at $17^{\circ} \mathrm{C}$.

In order to assess whether spleen and head kidney macrophages adhered equally well to the 96 well plate, $20 \mu \mathrm{l}$ of the cell suspension from either spleen or head kidney were suspended in $80 \mu \mathrm{l}$ DMEM medium in wells of a 96 well plate with flat bottom (Iwaki Microplate, International Medical) and incubated for $24 \mathrm{~h}$ at $17^{\circ} \mathrm{C}$ with $5 \% \mathrm{CO}_{2}$. After gently rinsing 3 times with $\mathrm{HBSS}$ at $17^{\circ} \mathrm{C}$, the cells were harvested by adding $20 \mu$ trypsin solution per well, based on $88 \mathrm{ml}$ trypsin diluent $\left(8 \mathrm{~g} \mathrm{NaCl}, 0.2 \mathrm{~g} \mathrm{KCl}, 0.12 \mathrm{~g} \mathrm{KH}_{2} \mathrm{PO}_{4}, 0.91 \mathrm{~g}\right.$ 
$\mathrm{NaH}_{2} \mathrm{PO}_{4}$, phenolred $0.5 \%$ and aqua dest $1000 \mathrm{ml}$ ), $10 \mathrm{ml}$ trypsin stock (25 $\mathrm{mg} \mathrm{ml}^{-1}$, Gibco) and $2 \mathrm{ml}$ versenate [2 g ethylenediamineteraacetic acid (EDTA) in $100 \mathrm{ml}$ trypsin diluent]. After $10 \mathrm{~min}$ incubation at $37^{\circ} \mathrm{C}$ with $5 \% \mathrm{CO}_{2}$, the cells were re-suspended in $100 \mu \mathrm{l}$ DMEM and counted using a Burker counting chamber. No differences in adhesive capacity were noticed between the 2 cell populations.

Bactericidal activity of rainbow trout macrophages against Flavobacterium psychrophilum. The bactericidal activity of spleen and head kidney macrophages against both Flavobacterium psychrophilum strains was evaluated. For this purpose, the macrophages were rinsed gently 3 times with HBSS after $24 \mathrm{~h}$ incubation at $17^{\circ} \mathrm{C}$ with $5 \% \mathrm{CO}_{2}$. Then, $25 \mu \mathrm{l}$ of the bacterial suspension containing $10^{7} \mathrm{CFU}$ of F. psychrophilum was added to the macrophages. Wells without macrophages were likewise inoculated and served as negative controls. The plates were centrifuged at $380 \times g$ for $10 \mathrm{~min}$ at $17^{\circ} \mathrm{C}$ to bring the bacteria into contact with the cells. After $2 \mathrm{~h}$ of incubation at $17^{\circ} \mathrm{C}$ with $5 \% \mathrm{CO}_{2}$, the macrophages were lysed by the addition of $200 \mu \mathrm{l}$ of distilled water, pipetted 30 times and subsequently shaken for $10 \mathrm{~min}$. Fifty $\mu \mathrm{l}$ of 10 -fold serial dilutions were plated in triplicate on Shieh agar and incubated for $4 \mathrm{~d}$ at $17^{\circ} \mathrm{C}$. In the negative control wells, the bacteria were enumerated before and after incubation. The bacterial numbers remained stable (approximately $\left.10^{7}\right)$. The experiment was conducted in triplicate and repeated 4 times. Data are presented using the following bacterial survival rate (BS):

$$
\mathrm{BS}=\frac{\text { Bacterial count at } 2 \mathrm{~h} \text { post inoculation }}{\text { Average of bacterial count of the negative }} \times 100
$$

In order to visualise the association of both Flavobacterium psychrophilum strains with the macrophages, spleen macrophages were seeded at a concentration of $10^{6}$ cells on glass coverslips in a 24 well cell culture plate (Greiner) and inoculated with one of both bacterial strains as described above at an MOI (multiplicity of infection) of 100 . After $2 \mathrm{~h}$ of incubation at $17^{\circ} \mathrm{C}$ and $5 \% \mathrm{CO}_{2}$, the coverslips were rinsed with $\operatorname{HBSS}\left(17^{\circ} \mathrm{C}\right)$ 3 times and stained using Haemacolor ${ }^{\circledR}$ (Merck). The average number of flavobacteria associated per macrophage per bacterial strain was determined by counting the number of bacteria associated with 50 cells, using light microscopy at a magnification of $100 \times$. This experiment was performed in duplicate on the macrophages from 2 fish.

Production of reactive oxygen species by rainbow trout macrophages inoculated with Flavobacterium psychrophilum. The generation of reactive oxygen species (ROS) by spleen and head kidney macrophages was determined using the chemiluminescence assay (CL). The assays were performed in a microplate luminometer (Fluoroscan Ascent Fl, Thermo Labsystems), using 96 well plates with clear bottoms (Greiner bio-one) at $17^{\circ} \mathrm{C}$. Luminol (Sigma Biosciences) was used as luminescent probe. Luminol was dissolved in dimethyl sulfoxide (DMSO, Sigma Biosciences) to give a concentration of $104 \mathrm{mM}$ and was stored in small aliquots at $-70^{\circ} \mathrm{C}$. Prior to use, the luminol stock was thawed and diluted in HBSS to a final concentration of $200 \mu \mathrm{M}$.

The cell culture medium was replaced by $100 \mu \mathrm{l}$ HBSS and $25 \mu$ l of diluted luminol solution in HBSS, the plates were placed in the luminometer and the CL background value was recorded for $10 \mathrm{~min}$. The data were collected at 2 min intervals and the CL response was recorded for $2 \mathrm{~h}$. After stabilization of the background value, $50 \mu \mathrm{l}$ of suspension containing $10^{7} \mathrm{CFU}$ of either of the bacterial strains were added per well. The addition of $50 \mu \mathrm{l}$ of phorbol myristate acetate (PMA, Sigma), final concentration $70 \mu \mathrm{g} \mathrm{ml}^{-1}$, to non-infected macrophages was used as positive control. Negative control samples were included in each CL assay. Each CL assay was performed 8 times in duplicate or triplicate, depending on the macrophage yield. The production of ROS over the $2 \mathrm{~h}$ period is presented as 'area under the curve (AUC)'.

Cytotoxicity of Flavobacterium psychrophilum to rainbow trout macrophages. In order to measure cytotoxic effects of the low and highly virulent strain on head kidney and spleen macrophages, the release of lactate dehydrogenase (LDH, Roche) from infected macrophages was assessed according to the method of Korzenieweski \& Callewaert (1983) with some modifications. Inoculation of the macrophages was performed as described previously. Uninoculated wells were used as negative controls. Positive control samples consisted of macrophages in $175 \mu \mathrm{l}$ medium, lysed with $25 \mu \mathrm{l}$ of $2 \%$ Triton X-100 for $15 \mathrm{~min}$. Following centrifugation $\left(250 \times g, 10 \mathrm{~min}, 4^{\circ} \mathrm{C}\right)$, the LDH level of the supernatant was determined according to the manufacturer's instructions. The absorbency at $492 \mathrm{~nm}$ was recorded using an ELISA reader (Titertek). The percentage cytotoxicity was calculated using the following formula:

$$
\text { Cytotoxity }=\frac{\begin{array}{c}
\text { Absorbency }- \text { Average } \\
\text { absorbency negative control }
\end{array}}{\begin{array}{l}
\text { Average absorbency positive control }- \\
\text { Average absorbency negative control }
\end{array}} \times 100
$$

Sensitivity of Flavobacterium psychrophilum strains to $\mathbf{H}_{2} \mathbf{O}_{2}$. The sensitivity of both the low and the highly virulent strain to $\mathrm{H}_{2} \mathrm{O}_{2}$ was determined. Five ml of each of the bacterial suspensions containing $10^{7} \mathrm{CFU} \mathrm{ml}{ }^{-1}$ were mixed with $5 \mathrm{ml}$ of Shieh broth containing $40 \mathrm{mM} \mathrm{H}_{2} \mathrm{O}_{2}$ and incubated at $17^{\circ} \mathrm{C}$. After 
30 min incubation, the number of CFU was counted by plating 10-fold serial dilutions on Shieh agar plates in triplicate. In order to detect catalase activity in both strains, a loopful of bacteria was suspended in a $3 \%$ $\mathrm{H}_{2} \mathrm{O}_{2}$ solution and the formation of $\mathrm{O}_{2}$ bubbles was determined.

Statistical analysis. We compared the results from the low and highly virulent strain and from the head kidney and spleen macrophages. For all comparisons, the paired $t$-test was used (computer program Sigma Stat, Analytical Software). A value of $\mathrm{p}<0.05$ was considered statistically significant.

\section{RESULTS}

\section{Bactericidal activity of rainbow trout macrophages against Flavobacterium psychrophilum}

The bactericidal activity of the spleen and head kidney macrophages exposed to strains Dubois and 99/10A is shown in Fig. 1. The bacterial cells of the highly virulent strain were killed 11.0 times less by head kidney macrophages than those of the low virulent strain, and 5.8 times less by spleen macrophages $(p<0.05)$. The head kidney macrophages demonstrated a bactericidal activity which was approximately twice as high as the spleen macrophages ( $\mathrm{p}<$ 0.05). No difference in association with the macrophages was noticed between the 2 strains.

\section{Production of reactive oxygen species by rainbow trout macrophages inoculated with Flavobacterium psychrophilum}

Results are summarized in Fig. 2. Both spleen and head kidney macrophages produced ROS upon stimulation with both strains. The level of ROS production induced by Strain Dubois was 2- to 3-fold higher than that induced by Strain 99/10A in both spleen and head kidney macrophages $(p<0.05)$. Approximately 2 to 3 times more ROS were produced by the head kidney macrophages than by the spleen macrophages $(p<0.05)$.

\section{Cytotoxicity of Flavobacterium psychrophilum strains for rainbow trout macrophages}

Both Flavobacterium psychrophilum strains were cytotoxic for both spleen and head kidney macrophages (Fig. 3). In spleen macrophages but not in head kidney macrophages, the cytotoxic effect of the highly virulent strain was twice as high as that of the low virulent strain $(\mathrm{p}<0.05)$.

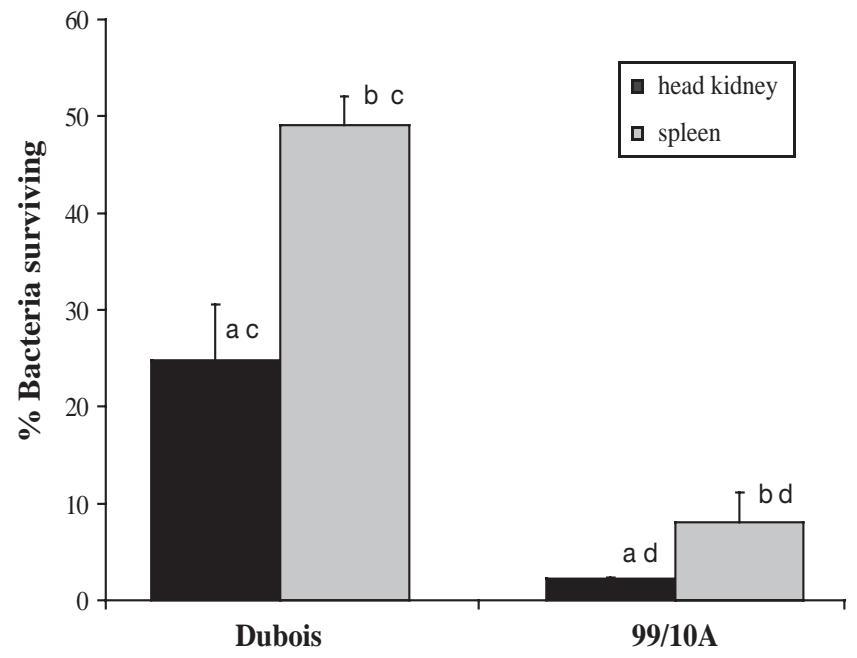

Fig. 1. Oncorhynchus mykiss. Average percentages of surviving bacteria + SE of a low (99/10A) and a highly (Dubois) virulent strain of Flavobacterium psychrophilum at $2 \mathrm{~h}$ post exposure to spleen and head kidney rainbow trout macrophages. Data represents the mean of 4 independent experiments $(+\mathrm{SE})$. The same letter $(\mathrm{a}-\mathrm{d})$ refers to a statistically significant difference

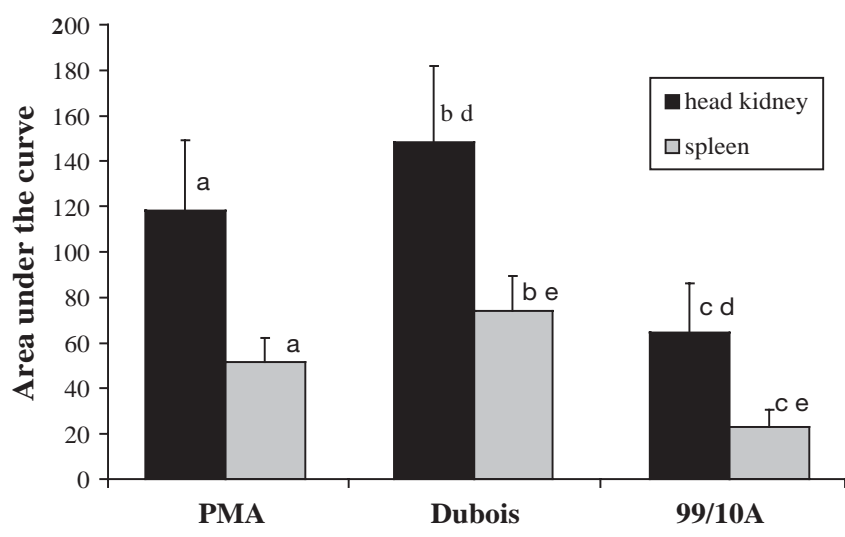

Fig. 2. Oncorhynchus mykiss. Mean ROS production + SE of spleen or head kidney macrophages from rainbow trout after exposure to phorbol myristate acetate (PMA) a low (99/10A) or a highly virulent (Dubois) strain of Flavobacterium psychrophilum. Data represents the mean of 8 independent experiments $(+\mathrm{SE})$. The same letter $(\mathrm{a}-\mathrm{e})$ refers to a statistically significant difference

\section{Sensitivity of Flavobacterium psychrophilum strains to $\mathrm{H}_{2} \mathrm{O}_{2}$}

Bacterial survival of Flavobacterium psychrophilum after exposure to $\mathrm{H}_{2} \mathrm{O}_{2}$ is shown in Fig. 4. The low virulent strain was killed approximately 10 times more over the $30 \mathrm{~min}$ period than the highly virulent strain $(p<0.05)$. Weak catalase activity was found in both $F$. psychrophilum strains. 


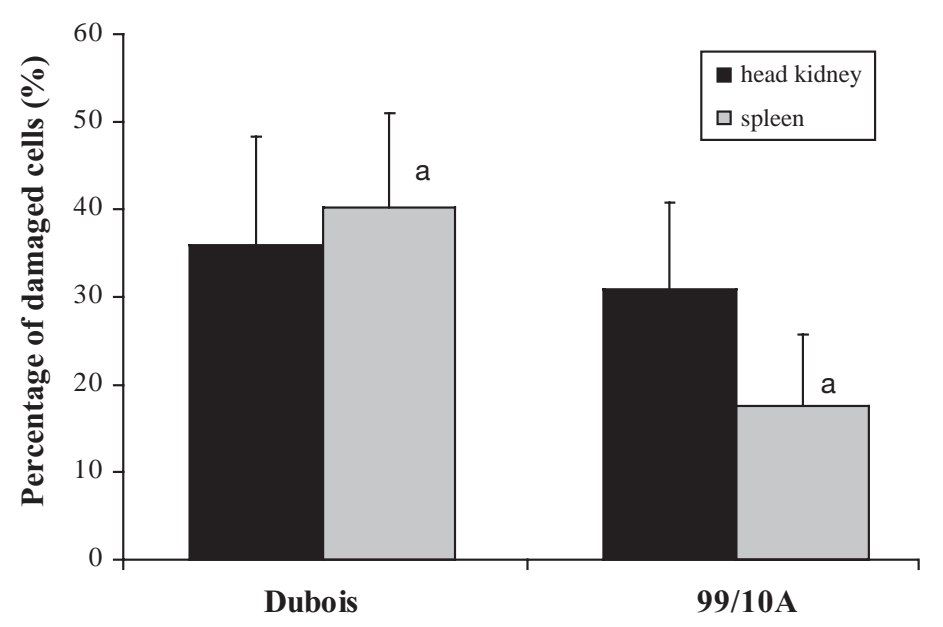

Fig. 3. Oncorhynchus mykiss. Cytotoxic effect of a low (99/10A) and a highly (Dubois) virulent strain of Flavobacterium psychrophilum on spleen or head kidney macrophages from rainbow trout. The data are presented as mean $\%$ of damaged cells + SE of 4 independent experiments. The same letter refers to a statistically significant difference

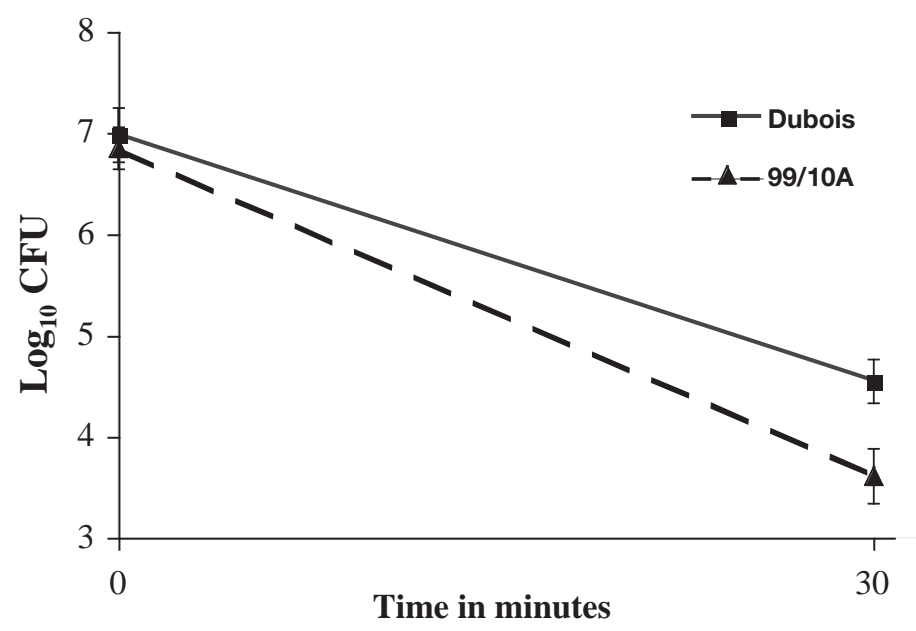

Fig. 4. Oncorhynchus mykiss. Survival of a low (99/10A) and a highly (Dubois) virulent strain of Flavobacterium psychrophilum after exposure to $\mathrm{H}_{2} \mathrm{O}_{2}$. The data are presented as the average $\log (10)$ decrease of the number of CFU between 0 and 30 min after exposure \pm SE of 4 independent experiments

\section{DISCUSSION}

In the present study, early interactions of a low and a highly virulent Flavobacterium psychrophilum strains with spleen and head kidney macrophages of rainbow trout were determined.

Both spleen and head kidney macrophages were able to kill at least a certain percentage of both Flavobacterium psychropilum strains. Despite stronger induction of reactive oxygen species production (ROS) by both spleen and head kidney macrophages, a higher proportion of the highly virulent strain survived. Wiklund \& Dalsgaard (2003) found low virulent strains to be strongly associated with head kidney phagocytes. This strong association may result in a higher rate of killing as shown in this study. However, both strains used in our experiments adhered equally well to the macrophages. This finding suggests that the difference in bacterial survival between the 2 strains is due to a difference in resistance to killing by macrophages.

Likewise, our finding correlates well with the lower sensitivity of the highly virulent strain, as against the low virulent strain, to killing by $\mathrm{H}_{2} \mathrm{O}_{2}$, although both strains showed weak catalase activity. Several mechanisms that protect Flavobacterium spp. from ROS, such as superoxide dismutase (SOD) and catalase activity have been described previously (Sanchez-Moreno et al. 1989, Kawai et al. 2000, Nematollahi et al. 2003). The presence or enhanced expression of one of these mechanisms in the highly virulent strain may account for higher resistance to killing by ROS. Hence, resistance to bacterial killing by the host macrophages may constitute an important virulence factor of F. psychrophilum, thus confirming the results of Decostere et al. (2001). Circumventing of the macrophage's killing mechanisms has been described previously in other fish pathogens such as Renibacterium salmoninarum and Aeromonas salmonicida (Campos-Pérez et al. 1997, Barnes et al. 1999).

The head kidney macrophages produced more ROS and killed more bacteria than did the spleen macrophages. This finding suggests that spleen macrophages are more tolerant towards harbouring Flavobacterium psychrophilum bacteria and, hence, may constitute a safer niche in which the bacterium can reside. This hypothesis is supported by earlier in vivo studies, in which the spleen proved to be one of the target organs of the bacterium, as opposed to the head kidney (Chua 1991, Rangdale et al. 1999).

Interestingly, Flavobacterium psychrophilum proved to be cytotoxic for trout macrophages, resulting in fairly high losses of viable macrophages at $2 \mathrm{~h}$ post inoculation. These results are not in agreement with those of Wiklund \& Dalsgaard (2003) who demonstrated only very limited cytotoxic effects. The reasons for this difference are not clear but different experimental protocols, bacterial strains and culture conditions may possibly play a role.

Several facultatively intracellular bacteria, for instance Salmonella spp., have been proven to induce cell death in infected macrophages (Van der Velden et al. 2000, Boise \& Collins 2001, Knodler \& Finlay 2001). In Salmonella spp., induction of macrophage cell death early after infection promotes intestinal inflammation 
and attraction of new macrophages to the intestinal mucosa. Inside these macrophages, the bacteria are able to spread systemically, for example to the spleen. Inside the internal organs, macrophage cell death promotes spreading of the organism to other macrophages. A similar process might be important in the pathogenesis of Flavobacterium psychrophilum infections. The higher cytotoxicity of the highly virulent strain as against the low virulent strain for the spleen macrophages might result in the organism spreading more rapidly to and within the spleen in vivo.

In conclusion, high virulence in Flavobacterium psychrophilum appears to be correlated with higher macrophage cytotoxicity and resistance to ROS and, therefore, with enhanced resistance to bacterial killing by rainbow trout macrophages. Furthermore, due to their lower ROS production, spleen macrophages are less antimicrobially active against F. psychrophilum than head kidney macrophages and, thus, might form a 'safe site' where the bacteria can reside.

Acknowledgements. Mr. G. Massaer is acknowledged for his skilled technical assistance. We would like to thank I. Dalsgaard (Danish Institute for Fisheries Research, Denmark) and F. Lieffrig (Centre d' Economie Rurale, Marloie, Belgium) for providing the Flavobacterium psychrophilum strains. The Ministry of Science, Research and Technology of Iran is also thanked for providing a scholarship to A.N.

\section{LITERATURE CITED}

Austin B, Austin DA (1999) Bacterial fish pathogens: disease of farmed and wild fish. Praxis Publishing, Chichester

Barnes AC, Bowden TJ, Horne MT, Ellis AE (1999) Peroxideinducible catalase in Aeromonas salmonocida subsp. salmonicida protects against exogenous hydrogen peroxide and killing by activated rainbow trout, Oncorhynchus mykiss L., macrophages. Microb Pathog 26:149-158

Bernardet JF, Sergers P, Vancanneyt M, Berthe F, Kersters K, Vandamme P (1996) Cutting a Gordian Knot: emended classification and description of the Genus Flavobacterium, emended description of the family Flavobacteriaceae, and proposal of Flavobacterium hydatis nom. nov. (Basonym, Cytophaga aquatilis Strohl and Tait 1978). Int J Syst Bacteriol 46:128-148

Boise LH, Collins CM (2001) Salmonella-induced cell death: apoptosis, necrosis or programmed cell death? Trends Microbiol 9:64-67

Borg AF (1960) Studies on myxobacteria associated with diseases in salmonid fishes. J Wildl Dis 8:1-85

Bruno DW (1992) Cytophaga psychrophila (= Flexibacter psychrophilus) (Borg), histopathology associated with mortalities among farmed rainbow trout, Oncorhynchus mykiss (Walbaum) in the UK. Bull Eur Assoc Fish Pathol 12: 215-216

Editorial responsibility: David Bruno, Aberdeen, UK
Campos-Pérez JJ, Ellis AE, Secombes CJ (1997) Investigation of factors influencing the ability of Renibacterium salmoninarum to stimulate rainbow trout macrophages respiratory burst activity. Fish Shellfish Immunol 7: $555-566$

Chua FHC (1991) A study on the rainbow trout fry syndrome. MSc thesis, University of Stirling

Davis HS (1946) Care and diseases of trout. US Dept Int Res Rep no. 12, US Government Printing Office, Washington, DC

Decostere A, D'Haese E, Lammens M, Nelis H, Haesebrouck F (2001) In vivo study of phagocytosis, intracellular survival and multiplication of Flavobacterium psychrophilum in rainbow trout, Oncorhynchus mykiss (Walbaum), spleen phagocytes. J Fish Dis 24:481-487

Holt RA, Rohevec JS, Fryer JL (1993) Bacterial coldwater disease. In: Inglis V, Roberts RJ, Bromage NR (eds) Bacterial diseases of fish. Blackwell Scientific, Oxford, p 3-23

Kawai Y, Okawara AI, Okuyama H, Kura F, Suzuki K (2000) Modulation of chemotaxis, $\mathrm{O}_{2}^{-}$production and myeloperoxidase release from human polymorphonuclear leukocytes by the ornithine-containing lipid and the serineglycine-containing lipid of Flavobacterium. Immunol Med Microbiol 28:205-209

Knodler LA, Finlay BB (2001) Salmonella and apoptosis: to live or to let die? Microbes Infect 3:1321-1326

Korzenieweski C, Callewaert DM (1983) An enzyme-release assay for natural cytotoxicity. J Immunol Methods 64: 313-320

Lammens M, Decostere A, Haesebrouck F (2000) Effects of Flavobacterium psychrophilum and their metabolites on the oxidative activity of rainbow trout Oncorhynchus mykiss phagocytes. Dis Aquat Org 41:173-179

Madsen L, Dalsgaard I (1998) Characterization of Flavobacterium psychrophilum; comparison of proteolytic activity and virulence of strains isolated from rainbow trout (Oncorhynchus mykiss). In: Barnes AC, Davidson GA, Hiney MP, McIntosh D (eds) Methodology in fish diseases research. Fisheries Research Services, Aberdeen, p 45-52

Nematollahi A, Decostere A, Pasmans F, Haesebrouck F (2003) Flavobacterium psychrophilum infections in salmonid fish. J Fish Dis 26:563-574

Rangdale RE, Richards RH, Alderman DJ (1999) Histopathological and electron microscopical observations on rainbow trout fry syndrome. Vet Rec 144:251-254

Sanchez-Moreno M, Monteoliva-Sanchez M, Ortega F, Ramos-Cormenzana A, Monteoliva M (1989) Superoxid dismutase in strains of the genus Flavobacterium: isolation and characterization. Arch Microbiol 152:407-410

Shieh HS (1980) Studies on the nutrition of a fish pathogen, Flexibacter columnaris. Microbios Lett 13:129-133

Van der Velden AWM, Lindgren SW, Worley MJ, Heffron F (2000) Salmonella pathogenicity island 1-independent induction of apoptosis in infected macrophages by Salmonella enterica serotype Typhimurium. Infect Immun 68: 5702-5709

Wiklund T, Dalsgaard I (2003) Association of Flavobacterium psychrophilum with rainbow trout (Oncorhynchus mykiss) kidney phagocytes in vitro. Fish Shellfish Immunol 15: 387-395

Submitted: May 30, 2004; Accepted: October 28, 2004

Proofs received from author(s): February 28, 2005 